\title{
Editorial
}

\section{Will personal marketing replace direct marketing?}

Journal of Direct, Data and Digital Marketing Practice (2007) 8, 287-288. doi:10.1057/palgrave.dddmp.4350071

The opening opinion piece of this volume of the Journal gives a fascinating view of the future. Written by Peter Simpson, one of the original founders of First Direct, it picks up on the three challenges facing direct marketers today - consumerism, integration and consolidation. In the new world of marketing as communications digitise, they will become increasingly more accountable and all marketing will become direct in the sense it is targeted, individual and measurable. Also, in the digital world, customer relationship management will be replaced by information management. While data is clearly a unit of value for marketers today, tomorrow it will become a unit of value to consumers who will trade it for better deals. Finally, Peter sees that mobile marketing is set to grow exponentially with the ability to track people on the move, their buyer behaviour and their communication preferences. He concludes with his four new Ps of marketing, and the future view of direct marketing will be defined as personal marketing, at the centre of information-led relationships. The real issue is will direct marketers rise to these new challenges or will classic advertisers make a comeback to dominate this new marketplace?

Our first paper picks up on the important issue of child protection from online marketing. Increasingly, children are spending more money online than ever before. This paper by Agnes Nairn of Bath University and Dowsiri Monkgol considers child data protection using the concepts of knowledge, control and parental involvement; reminds us of the DMA code of practice for online marketing to children; and presents a review of how 20 of the top children's websites match up to the code. This paper aims to highlight some of the issues involved in protecting children's online privacy and encourage debate on how the industry should proceed in this tricky area.

In contrast to this, our second paper is about the consumer and future prospect of enterprise marketing management (EMM) systems. It is by Carol Meyers, Head of Marketing, Unica Corporation. The findings are based on a survey of 300 services representatives across a range of industry sectors and are equally divided between France, Germany and the UK. It is interesting to read the contrast between the UK and French findings and the fact that only half of all respondents claimed to have heard of EMM. Despite holistic EMM solutions not being widespread in Europe, the findings indicated elements of EMM — personalised email and MRM — are increasingly common among European marketers.

Switching to integrated marketing, Professor Angus Jenkinson talks about how to optimise personalised customer strategies. This paper has implications for direct marketers and others who have responsibility for managing customer relationships or growing personal communication tailored to the interests and behaviour of segments or individuals.

Lastly, this volume considers a case history, on BT Campaign: Business Plan.

As editors we would be interested to hear your views on the future of direct marketing/marketing. Without doubt the digital revolution has set a new agenda for marketing but what will the fall-out look like - who will be the winners and who will be the losers; who are going to get the larger share of the marketing budgets? Our IDM Symposium this year is taking a future look at the 10 


\section{椋. Editorial}

supertrends that are going to change marketing's focus in the next 20 or so months. The Symposium, entitled '20:20 Vision' is on 15 May 2007, for more details visit the IDM website www.theidm.com/symposium.

Derek Holder

Robin Fairlie 